\title{
Stock Price Reaction to Seasoned Equity Offerings : Focusing on the Entertainment and Media Industry
}

\author{
Namgon Kim¹), Jee-Hyun Kim²)
}

\begin{abstract}
In a highly competitive business environment, raising capital is an important strategy for promoting a firm's growth. Stock market participants consider that the related announcements contain information related to the firm's value and affect investors' wealth. While theoretical studies provide several hypotheses to explain the stock price movements around seasoned equity offerings (SEOs), empirical research documents inconclusive results. The results mostly rely on aggregate market-wide data and, thus, are unable to disentangle industry-specific effects. Considering the rapidly growing importance of the entertainment and media (E\&M) sector in the economy, this study examines the stock price responses to the SEOs in the E\&M industry. To this end, this study analyzes a set of SEO events announced by E\&M firms for the period 2000 - 2019 in Korea. Adopting event study methodology, we find that, in general, SEO announcements are positively related to stock prices in the E\&M industry, supporting the investment opportunity hypothesis. Our investigation also reveals that the key factors, such as leverage, size, growth, and profitability, that affect stock price movements at the market level in prior studies do not exert any such influence in the E\&M industry. These findings indicate that test results based on a market-wide data are not completely applicable to firms in the E\&M industry, which is the rapidly growing but less comprehensively explored field and, thus, require investors to exercise caution when investing in this industry.
\end{abstract}

Keywords: Entertainment and Media Industry, Seasoned Equity Offerings, SEO Methods, Announcement Effect, Event Study

\section{Introduction}

This paper examines stock price reaction to equity issuing events in the entertainment and media (E\&M) industry. With the development of technologies, the E\&M industry is experiencing rapid growth worldwide. According to the PWC report[1], the global revenue of the E\&M industry is set to rise to USD 2.4 trillion in 2022, compared with USD 1.9 trillion in 2017. Considering that the global E\&M industry has been projected a compound annual growth

Received(April 11, 2020), Review Result(1st: June 6, 2020, 2nd: July 20, 2020), Accepted(July 27, 2020)

1) (Professor) 02748 Dept. Business Administration, Dongduk Women's Univ., Wolgok-dong, Sungbuk-gu, Seoul, Korea

email: fencer@dongduk.ac.kr

2) (Associate Professor, Corresponding Author) 24252 Finance Dept, Hallym Univ., Chuncheon-si, Gangwon-do, Korea

email: jhyunkim@hallym.ac.kr 
rate (CARG) of $4.4 \%$, the South Korean E\&M industry is one of the fastest-growing industries with a projected CAGR of $5.7 \%$. This growth is largely driven by the access to fast internet, well-established mobile networks, and the Korean wave or Hallyu, i.e., the popularity of high-quality Korean contents such as K-dramas and K-pop. In 2013, whereas South Korea's GDP ranked only 13th in the world, the Korean E\&M industry remarkably ranked 8th in terms of market size. Facing fierce competition due to the industry's growth, E\&M companies must raise external capital for their survival and growth. The issuance of stock by an already publicly-traded company to raise capital is referred to as seasoned equity offering (SEO).

The issuance of a large quantity of new stock will likely affect the issuing company and, subsequently, influence stock market participants. Prior theoretical research has provided several hypotheses, such as the price pressure, wealth redistribution, information release, and investment opportunity hypotheses, to explain stock price behavior surrounding SEO announcements. The price pressure hypothesis[2] states that increasing the number of shares dilutes the existing shareholders' value, which leads to a decrease in stock prices. The wealth redistribution hypothesis[3] contends that the decrease in leverage ratio caused by an increase in equity reduces debt risk. Consequently, bondholders enjoy the increase in debt value at the cost of shareholders' wealth, which can induce a negative stock price reaction. The information release hypothesis[4][5] supports the unfavorable stock market response to new stock issuance. It argues that firm insiders, who have access to more and better information, are reluctant to offer new equity when a firm has sufficiently profitable investment opportunities because it reduces their ownership share. Therefore, SEOs are interpreted as negative information. In contrast, the investment opportunity hypothesis[6] predicts a positive stock price response, stating that, by issuing new shares, firms can take on new profitable projects.

However, empirical evidence regarding these hypotheses is still inconclusive. While most studies that have analyzed developed markets, such as the U.S., have obtained results that stock price reacts unfavorably to SEO announcements, few studies have examined emerging markets. Unlike results regarding the U.S. market, a majority of research regarding the Korean market has reported positive stock returns in response to SEO announcements. More importantly, prior empirical studies have analyzed samples of firms from heterogeneous industries, largely ignoring industry-specific aspects.

In this context, despite the attention-grabbing nature of SEO events in the E\&M industry nowadays, research examining the influence of SEOs on stock prices and subsequently, shareholders' wealth is surprisingly scarce in this field. Analysis results regarding a specific industry or an emerging country may be different from those of market-wide analyses of 
developed countries[7-10].

Therefore, this study aims to assess how the E\&M industry perceives SEO events by investigating the behavior of E\&M firms' stock prices in response to these financial events. We expect this investigation to enhance our understanding of the E\&M industry, which has barely been explored from a financial viewpoint.

To this end, we analyze SEOs in the E\&M industry from two perspectives: stock price reactions to SEO announcements and the role of firm factors known to affect stock reactions in the existing literature. For these analyses, using SEOs announced by Korean E\&M firms from 2000 to 2019, we apply event study methodology to examine the impact of SEO announcements and multivariate regression analysis to explore the role of firm characteristics on the stock price reactions. For the former analysis, we use average abnormal return (AAR) variable and the cumulative average abnormal return (CAAR) variable. For the latter test, we use firm characteristic variables, such as sales growth rate, leverage ratio, return on equity (ROE), return on asset (ROA), and firm size. It is well-known that while most SEOs in the U.S. are offered to a large number of public investors, many SEO cases in Korea are only offered to a small number of specific investors. In this study, when assessing the effect of SEO announcements, we additionally examine whether there is a distinction between SEO methods, i.e., public and non-public equity offerings. Considering that the number of publicly traded E\&M firms in stock markets is rapidly increasing, the findings of this study would be beneficial for current and potential investors when making investment decisions and for financial managers seeking to raise equity to make financial decisions.

\section{Literature Review}

\subsection{The Effects of SEOs at the Market Level}

In several previous studies, SEOs have been actively discussed using samples from entire markets that comprise various industries. Using SEO events in the U.S. market between 1984 and 2007, Chan and Chan[11] examine stock return synchronicity. They find that stock return synchronicity is negatively related to SEOs and that this relation becomes stronger with less information symmetry. Gao and Ritter[12], also analyzing the U.S. market, report negative stock reactions of $-1.7 \%$. Huang et al.[13] analyze 101 SEO events in the Chinese market from 2006 to 2014 and observe a stock price reduction associated with the initial announcement of SEOs. More recently, Hibbert et al.[14] investigate stock market responses to SEO events, using stock 
return volatility rather than the average of stock returns; these findings support the information release hypothesis.

\subsection{The Effects of SEOs at the Industry Level}

Few recent studies have attempted to investigate the effects of SEOs in a specific industry. Colombo and Botta[15] examine the effects of SEO announcements in the banking industry for a sample period 2008-2014. Showing evidence that the disclosure regarding SEO activities hurts shareholders' wealth, they argue that, in the banking industry, SEO announcements have a significant signaling role. Focusing on the banking industry, Li et al.[16] assert that stock price responses could be positive or negative depending on the stringency of bank regulations.

\subsection{The Effects of SEOs based on the Equity-Raising Mechanisms}

While the negative effects of SEO events have been well documented at the market level, the differences in effects of different equity-selling methods have received relatively little attention in academic literature. Chen et al.[17] compare the traditional equity offerings and private investments in public equity (PIPE) of US firms for the period 1996-2006 and find that firms with high information asymmetry are more likely to prefer PIPEs. Analyzing more than 13,000 equity issues, Gomes and Phillips[18] find that asymmetric information is a primary determinant of the choice of private or public stock issuance.

While most studies regarding the choice of equity-raising mechanism have exclusively utilized samples comprising US-based firms, Dahiya et al.[19] conduct an analysis of firms in nine Asian countries. Unlike studies analyzing US-based firms, they find that asymmetric information or financial distress does not play an important role in the choice of equity issuance mechanism, and the determinants for the US and non-US firms do not completely overlap.

\section{Research Method and Empirical Results}

To investigate how the stock market perceives SEO events in the E\&M industry, we analyze the stock price behavior surrounding these events by adopting the event study method. Our sample covers a long period from January 2000 to December 2019 and focuses on SEO events announced by E\&M firms listed on the Korean stock market. While employing event study 
Asia-pacific Journal of Convergent Research Interchange

Vol.6, No.8, August 31 (2020), pp.123-133

http://dx.doi.org/10.47116/apjcri.2020.08.12

methodology, for robustness, we utilize both returns based on the capital asset pricing model (CAPM) and market returns as benchmarks of expected returns in the calculation of abnormal returns (AR). The cumulative abnormal return (CAR) refers to the sum of ARs over the event period. By computing the mean values of the ARs and CARs across companies, we obtain the average abnormal return (AAR) and the cumulative average abnormal return (CAAR).

[Fig. 1] depicts stock price movements surrounding the SEO announcements. Panel A shows the results of the event study where expected return was adjusted as the benchmark return. In Panel B, the market return was adjusted as the benchmark return. Both Panels A and B reveal clear upward trends in CAARs since Day-20. The price response indicates that the E\&M industry has a favorable view regarding raising capital. Considering that the E\&M industry is a growing industry with various business opportunities, these results are very plausible.

[Table 1] reports the AARs and CAARs for 20 days before and 10 days after the SEO announcement. The CAAR and AAR values are statistically significant positive from Day- 1 and Day-2, respectively. The CAARs consistently show statistically positive returns up to Day 10 and do not present any return reversals, suggesting that shareholders consider SEOs as events that will improve firm value.

[Table 1] SEO Announcement Effects: AAR and CAAR

Panel A. Event Study 1: CAPM-adjusted model

\begin{tabular}{|c|c|c|c|c|}
\hline Days & AAR & t-value & CAAR & t-value \\
\hline-20 & -0.00191 & -0.54873 & -0.00191 & -0.54873 \\
\hline-15 & -0.00433 & -1.30338 & -0.00380 & -0.34780 \\
\hline-14 & 0.00392 & 1.08602 & 0.00011 & 0.00940 \\
\hline-13 & 0.01092 & $2.72285^{* * *}$ & 0.01103 & 0.81697 \\
\hline-12 & 0.00687 & $1.78905^{*}$ & 0.01791 & 1.27484 \\
\hline-11 & 0.00079 & 0.24099 & 0.01870 & 1.31099 \\
\hline-10 & -0.00169 & -0.47598 & 0.01701 & 1.16315 \\
\hline-5 & 0.00321 & 0.87164 & 0.01541 & 0.85561 \\
\hline-4 & 0.00558 & 1.47050 & 0.02099 & 1.12116 \\
\hline-3 & -0.00064 & -0.17306 & 0.02035 & 1.04499 \\
\hline-2 & 0.00923 & $2.37188^{* *}$ & 0.02958 & 1.50956 \\
\hline-1 & 0.01936 & 4.68020 & 0.04894 & $2.36657^{* *}$ \\
\hline 0 & 0.01935 & $3.93837^{* * *}$ & 0.06830 & $3.19703^{* * *}$ \\
\hline 1 & -0.00194 & -0.36699 & 0.06635 & $2.87383^{* * *}$ \\
\hline 2 & -0.00284 & -0.64832 & 0.06351 & $2.60246^{* * *}$ \\
\hline 3 & 0.00703 & $1.87350^{*}$ & 0.07054 & $2.73859^{* * *}$ \\
\hline 4 & 0.00493 & 1.14127 & 0.07547 & $2.80881^{* * *}$ \\
\hline 5 & -0.00571 & -1.51461 & 0.06977 & $2.57600^{* * *}$ \\
\hline 6 & -0.00491 & -1.27049 & 0.06485 & $2.38560^{* *}$ \\
\hline 7 & 0.00172 & 0.41001 & 0.06657 & $2.36847^{* *}$ \\
\hline 8 & -0.00514 & -1.45628 & 0.06144 & $2.17830^{* *}$ \\
\hline & & & & \\
\end{tabular}

Panel B. Event Study 2: Market-adjusted model

\begin{tabular}{|c|c|c|c|c|}
\hline Days & AAR & t-value & CAAR & t-value \\
\hline-20 & -0.000819 & -0.250639 & -0.000819 & -0.250639 \\
\hline-15 & -0.005420 & -1.568178 & -0.004514 & -0.434783 \\
\hline-14 & 0.002702 & 0.791577 & -0.001812 & -0.159855 \\
\hline-13 & 0.009254 & $2.361072^{* *}$ & 0.007442 & 0.596027 \\
\hline-12 & 0.006533 & 1.689850 & 0.013975 & 1.080263 \\
\hline-11 & 0.000864 & 0.264548 & 0.014838 & 1.123932 \\
\hline-10 & -0.002203 & -0.654699 & 0.012635 & 0.965585 \\
\hline-5 & 0.004881 & 1.361255 & 0.015748 & 1.050064 \\
\hline-4 & 0.004505 & 1.175771 & 0.020253 & 1.275751 \\
\hline-3 & 0.000151 & 0.041831 & 0.020404 & 1.256170 \\
\hline-2 & 0.008922 & $2.297466^{* *}$ & 0.029325 & 1.792598 \\
\hline-1 & 0.018019 & $4.418652^{* * *}$ & 0.047345 & $2.727558^{* * *}$ \\
\hline 0 & 0.018814 & $3.881806^{* * *}$ & 0.066159 & $3.6237289^{* * *}$ \\
\hline 1 & -0.003021 & -0.556528 & 0.063138 & $3.301288^{* * *}$ \\
\hline 2 & -0.003707 & -0.881204 & 0.059431 & $2.932482^{* * *}$ \\
\hline 3 & 0.005954 & 1.560769 & 0.065386 & $3.036761^{* * *}$ \\
\hline 4 & 0.006139 & 1.412489 & 0.071525 & $3.155319^{* * *}$ \\
\hline 5 & -0.003944 & -1.067709 & 0.067581 & $2.965619^{* * *}$ \\
\hline 6 & -0.002940 & -0.764201 & 0.064640 & $2.835816^{* * *}$ \\
\hline 7 & 0.002040 & 0.499431 & 0.066680 & $2.830822^{* * *}$ \\
\hline 8 & -0.005473 & -1.579124 & 0.061207 & $2.592291^{* * *}$ \\
\hline
\end{tabular}


Stock Price Reaction to Seasoned Equity Offerings : Focusing on the Entertainment and Media Industry

\begin{tabular}{|c|c|c|c|c|c|c|c|c|c|}
\hline 9 & -0.00038 & -0.09883 & 0.06106 & $2.17306^{* *}$ \\
\hline 10 & -0.00315 & -0.80219 & 0.05790 & $2.05978^{* *}$ \\
\hline
\end{tabular} \begin{tabular}{c|c|c|c|c|}
\hline 9 & 0.000964 & 0.251166 & 0.062171 & $2.697531^{* * *}$ \\
\hline 10 & -0.001504 & -0.396459 & 0.060667 & $2.683355^{* * *}$ \\
\hline
\end{tabular}

[Table 2] reports the CAARs around SEOs for various time windows: $[-1,1],[-5,5],[-10,5]$, and $[-10,10]$. Both event study methods, the CAPM-adjusted (Panel A) and market-adjusted models (Panel B), show that stock price behavior differs depending on the SEO method, i.e., public versus non-public offerings. In Panel A, the CAR[-1, 1] associated with public SEOs is - 0.0134, while it is 0.0485 for non-public SEOs. The difference between public and non-public SEOs is statistically significant at the $1 \%$ level. In Panel B, similar stock responses are observed with even more distinctions for all event windows.

[Table 2] Market Reaction: Public vs. Non-Public SEOs

Panel A: Event study 1 (CAPM-adjusted model)

\begin{tabular}{|c|c|c|c|}
\hline & Public & Non-Public & $\mathrm{t}$-value \\
\hline CAR[-1,1] & -0.0134 & 0.0485 & $3.44^{* * *}$ \\
\hline CAR[-5,5] & 0.0335 & 0.0599 & 0.75 \\
\hline CAR[-10,5] & 0.0416 & 0.0777 & 0.84 \\
\hline CAR[-10,10] & 0.0282 & 0.0727 & 0.99 \\
\hline
\end{tabular}

Panel B: Event Study 2 (Market-adjusted model)

Subsequently, we investigate stock price reactions based on the choice of equity-selling methods more thoroughly, and the results are provided in [Fig. 2] and [Table 3]. [Fig. 2] shows the stock price movements surrounding SEO announcements by depicting AARs and CAARs from 20 days before the announcements. Regarding non-public SEOs, we notice an upward increase in CAARs without return reversal afterwards, indicating an increase in the firm's intrinsic value. Meanwhile, Panel $B$ shows that CAARs decline continuously in the post-announcement period.

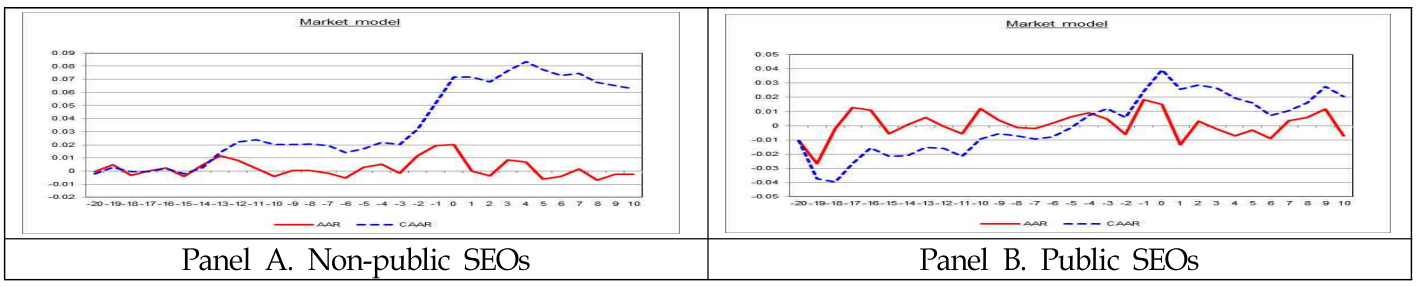

[Fig. 3] SEO announcement effects: CAPM-adjusted model (Event Study 1)

[Table 3] provides detailed information regarding AAR and CAAR values to compare the different stock responses to non-public and public SEOs. Non-public SEOs report statistically significantly positive CAARs from Day-1 to Day 10 . We find that the CAARs maintain an upward trend until Day 7 with a value of 0.0745. Even after Day 7, the CAARs do not 
Asia-pacific Journal of Convergent Research Interchange Vol.6, No.8, August 31 (2020), pp.123-133 http://dx.doi.org/10.47116/apjcri.2020.08.12 demonstrate rapid decline. However, when the SEO is offered to the general public, as presented in Panel B, the CAARs show a downward trend in the post-announcement period.

[Table 3] AARs and CAARs in Event Study 1 : Non-public SEOs vs. Public SEOs

Panel A. Non-Public SEOs

\begin{tabular}{|c|c|c|c|c|}
\hline Days & AAR & t-value & CAAR & t-value \\
\hline-20 & -0.0005 & -0.124770 & -0.0005 & -0.124770 \\
\hline-10 & -0.0040 & -0.988323 & 0.0200 & 1.167605 \\
\hline-5 & 0.0027 & 0.647051 & 0.0168 & 0.784321 \\
\hline-4 & 0.0050 & 1.161131 & 0.0219 & 0.990250 \\
\hline-3 & -0.0015 & -0.345771 & 0.0204 & 0.881984 \\
\hline-2 & 0.0118 & 2.573970 & 0.0321 & 1.389650 \\
\hline-1 & 0.0195 & $3.987503^{* * *}$ & 0.0517 & $2.108129^{* *}$ \\
\hline 0 & 0.0200 & $3.410889^{* * *}$ & 0.0717 & $2.812619^{* * *}$ \\
\hline 1 & 0.0000 & -0.002357 & 0.0717 & $2.635722^{* * *}$ \\
\hline 2 & -0.0038 & -0.742418 & 0.0679 & $2.363101^{* *}$ \\
\hline 3 & 0.0086 & $1.974946^{* *}$ & 0.0765 & $2.522080^{* *}$ \\
\hline 4 & 0.0069 & 1.360937 & 0.0834 & $2.630371^{* * *}$ \\
\hline 5 & -0.0061 & -1.395326 & 0.0773 & $2.411699^{* *}$ \\
\hline 6 & -0.0042 & -0.958972 & 0.0730 & $2.276997^{* *}$ \\
\hline 7 & 0.0014 & 0.299902 & 0.0745 & $2.258590^{* *}$ \\
\hline 8 & -0.0069 & $-1.703087^{*}$ & 0.0676 & $2.052766^{* *}$ \\
\hline 9 & -0.0024 & -0.554921 & 0.0652 & $1.984189^{* *}$ \\
\hline 10 & -0.0025 & -0.557430 & 0.0627 & $1.913929^{*}$ \\
\hline
\end{tabular}

Panel B. Public SEOs

\begin{tabular}{|c|c|c|c|c|}
\hline Days & AAR & $\mathrm{t}$-value & CAAR & $\mathrm{t}$-value \\
\hline-20 & -0.01042 & -1.96510 & -0.01042 & -1.96510 \\
\hline-10 & 0.01201 & 2.25292 & -0.00958 & -0.52457 \\
\hline-5 & 0.00604 & 1.13194 & -0.00174 & -0.08991 \\
\hline-4 & 0.00888 & 1.55777 & 0.00714 & 0.31865 \\
\hline-3 & 0.00467 & 1.21854 & 0.01181 & 0.52564 \\
\hline-2 & -0.00602 & -1.32195 & 0.00579 & 0.24720 \\
\hline-1 & 0.01830 & $3.80717^{* * *}$ & 0.02409 & 1.01591 \\
\hline 0 & 0.01510 & $2.97304^{* * *}$ & 0.03919 & $1.77719^{*}$ \\
\hline 1 & -0.01353 & -1.64476 & 0.02567 & 0.92502 \\
\hline 2 & 0.00303 & 0.55503 & 0.02870 & 0.96542 \\
\hline 3 & -0.00241 & -0.48068 & 0.02629 & 0.84281 \\
\hline 4 & -0.00709 & -1.39774 & 0.01920 & 0.60726 \\
\hline 5 & -0.00312 & -0.63315 & 0.01608 & 0.51536 \\
\hline 6 & -0.00898 & -1.54833 & 0.00709 & 0.22150 \\
\hline 7 & 0.00339 & 0.54760 & 0.01048 & 0.30053 \\
\hline 8 & 0.00556 & 1.13042 & 0.01605 & 0.43731 \\
\hline 9 & 0.01149 & $1.75765^{*}$ & 0.02754 & 0.76276 \\
\hline 10 & -0.00706 & -1.19792 & 0.02048 & 0.55284 \\
\hline
\end{tabular}

For the robustness, we also conduct a market-adjusted event study and the results are shown in [Fig. 3] and [Table 4]. In this event study, the differences in stock market reactions are more profound. Stock prices react positively to non-public SEO announcements (Panel A) and very negatively to public SEO announcements. Panel B shows that the CAAR has declined even 20 days before the SEO announcement, indicating the existence of information leakage in the market prior to the official announcement to the public. [Table 4] provides detailed daily responses of stock returns in terms of the AARs and CAARs.

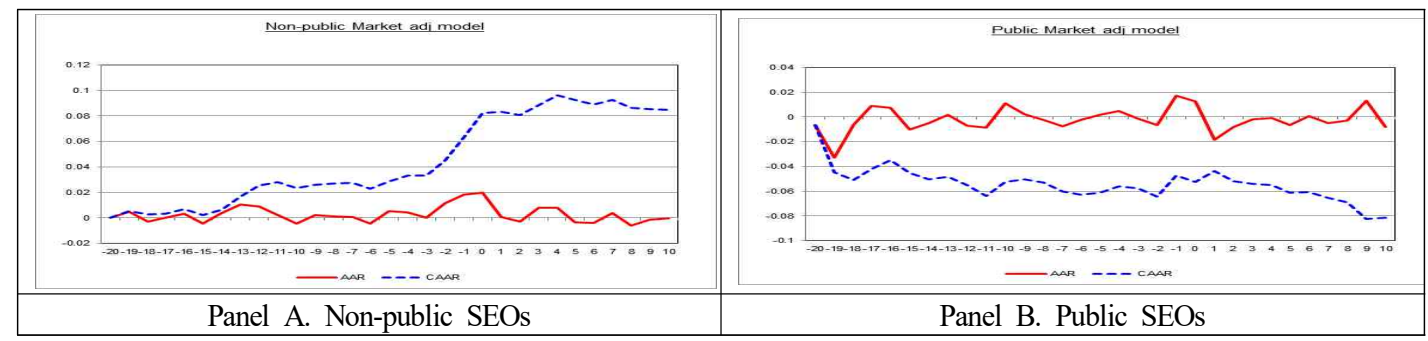

[Fig. 4] SEO Announcement Effects: Using CAPM-adjusted Model (Event Study 2) 
[Table 4] AARs and CAARs in Event Study 2 : Non-public SEOs vs. Public SEOs

Panel A. Non-Public SEOs

\begin{tabular}{|c|c|c|c|c|}
\hline Days & AAR & P-Value & CAAR & P-Value \\
\hline-20 & 0.000114 & 0.975417 & 0.000114 & 0.975417 \\
\hline-19 & 0.004678 & 0.281423 & 0.005639 & 0.346767 \\
\hline-18 & -0.002655 & 0.537145 & 0.002984 & 0.700341 \\
\hline-17 & 0.000406 & 0.920389 & 0.003389 & 0.736910 \\
\hline-16 & 0.003500 & 0.346351 & 0.006889 & 0.537258 \\
\hline-15 & -0.004652 & 0.231830 & 0.002237 & 0.849742 \\
\hline-14 & 0.004004 & 0.319980 & 0.006242 & 0.632345 \\
\hline-13 & 0.010488 & 0.029213 & 0.016730 & 0.250120 \\
\hline-12 & 0.008761 & 0.050569 & 0.025490 & 0.087806 \\
\hline-11 & 0.002422 & 0.525231 & 0.027912 & 0.068605 \\
\hline-10 & -0.004406 & 0.252441 & 0.023507 & 0.122728 \\
\hline-9 & 0.002265 & 0.583679 & 0.025772 & 0.106550 \\
\hline-8 & 0.001087 & 0.777908 & 0.026858 & 0.096758 \\
\hline-7 & 0.000675 & 0.856978 & 0.027533 & 0.094216 \\
\hline-6 & -0.004400 & 0.246086 & 0.023134 & 0.152203 \\
\hline-5 & 0.005409 & 0.189425 & 0.028543 & 0.105333 \\
\hline-4 & 0.004462 & 0.313800 & 0.033005 & 0.074699 \\
\hline-3 & 0.000396 & 0.926489 & 0.033401 & 0.078865 \\
\hline-2 & 0.011512 & 0.014202 & 0.044913 & 0.018726 \\
\hline-1 & 0.018185 & 0.000240 & 0.063098 & 0.002151 \\
\hline 0 & 0.019818 & 0.000796 & 0.082035 & 0.000180 \\
\hline 1 & 0.000515 & 0.931155 & 0.083176 & 0.000296 \\
\hline 2 & -0.002640 & 0.586066 & 0.080536 & 0.000888 \\
\hline 3 & 0.007784 & 0.078424 & 0.088320 & 0.000579 \\
\hline 4 & 0.007764 & 0.127444 & 0.096084 & 0.000398 \\
\hline 5 & -0.003339 & 0.424900 & 0.092744 & 0.000632 \\
\hline 6 & -0.003826 & 0.371732 & 0.088918 & 0.000976 \\
\hline 7 & 0.003682 & 0.436091 & 0.092600 & 0.000806 \\
\hline 8 & -0.006020 & 0.134155 & 0.086579 & 0.001508 \\
\hline 9 & -0.001423 & 0.743136 & 0.085157 & 0.001633 \\
\hline 10 & -0.000242 & 0.955596 & 0.084915 & 0.001264 \\
\hline & & & & \\
\hline
\end{tabular}

Panel B. Public SEOs

\begin{tabular}{|c|c|c|c|c|}
\hline Days & AAR & P-Value & CAAR & P-Value \\
\hline-20 & -0.00642 & 0.53543 & -0.00642 & 0.53543 \\
\hline-19 & -0.03307 & 0.00528 & -0.04457 & 0.01847 \\
\hline-18 & -0.00634 & 0.47149 & -0.05091 & 0.02190 \\
\hline-17 & 0.00876 & 0.41641 & -0.04215 & 0.08843 \\
\hline-16 & 0.00716 & 0.52884 & -0.03499 & 0.19796 \\
\hline-15 & -0.01003 & 0.38552 & -0.04502 & 0.16013 \\
\hline-14 & -0.00511 & 0.54521 & -0.05013 & 0.12414 \\
\hline-13 & 0.00185 & 0.76743 & -0.04829 & 0.14448 \\
\hline-12 & -0.00683 & 0.53512 & -0.05512 & 0.12920 \\
\hline-11 & -0.00849 & 0.32635 & -0.06360 & 0.07140 \\
\hline-10 & 0.01101 & 0.27503 & -0.05259 & 0.13137 \\
\hline-9 & 0.00201 & 0.84299 & -0.05058 & 0.15721 \\
\hline-8 & -0.00227 & 0.84226 & -0.05285 & 0.14286 \\
\hline-7 & -0.00739 & 0.46627 & -0.06024 & 0.10307 \\
\hline-6 & -0.00249 & 0.81266 & -0.06273 & 0.07963 \\
\hline-5 & 0.00171 & 0.87391 & -0.06102 & 0.09916 \\
\hline-4 & 0.00476 & 0.66870 & -0.05626 & 0.18063 \\
\hline-3 & -0.00132 & 0.87115 & -0.05758 & 0.17009 \\
\hline-2 & -0.00662 & 0.38657 & -0.06420 & 0.13472 \\
\hline-1 & 0.01703 & 0.08208 & -0.04717 & 0.26933 \\
\hline 0 & 0.01263 & 0.22335 & -0.05236 & 0.20073 \\
\hline 1 & -0.01834 & 0.32019 & -0.04364 & 0.33480 \\
\hline 2 & -0.00833 & 0.49649 & -0.05197 & 0.28694 \\
\hline 3 & -0.00197 & 0.85619 & -0.05394 & 0.30952 \\
\hline 4 & -0.00090 & 0.93910 & -0.05484 & 0.31657 \\
\hline 5 & -0.00656 & 0.56933 & -0.06141 & 0.27451 \\
\hline 6 & 0.00090 & 0.94356 & -0.06051 & 0.29983 \\
\hline 7 & -0.00507 & 0.66227 & -0.06558 & 0.29760 \\
\hline 8 & -0.00310 & 0.75523 & -0.06868 & 0.30842 \\
\hline 9 & 0.01298 & 0.28051 & -0.08256 & 0.17040 \\
\hline 10 & -0.00807 & 0.47704 & -0.08107 & 0.18896 \\
\hline & & & & \\
\hline
\end{tabular}

Additionally, we investigate whether firm characteristics, known for affecting stock price reactions in existing market-level studies, exert a similar influence in the E\&M industry as well. The results reported in [Table 5] reveal no statistically significant influence of firm characteristics, such as sales growth rate, leverage ratio, return on equity (ROE), return on asset (ROA), and firm size, in the E\&M industry.

[Table 5] Regressions : CAARs and Firm Characteristics

\begin{tabular}{|c|c|c|c|c|c|c|}
\hline Variable & CAR[-5,5] & $\mathrm{t}$-value & CAR[-5,5] & $\mathrm{t}$-value & CAR[-1,1] & $\mathrm{t}$-value \\
\hline Intercept & -0.01409 & -0.19 & -0.02623 & -0.34 & -0.00384 & -0.05 \\
\hline Sales growth rate & -0.00135 & -0.11 & 0.00894 & 0.7 & -0.00178 & -0.14 \\
\hline
\end{tabular}




\begin{tabular}{|c|c|c|c|c|c|c|}
\hline Leverage & -0.01713 & -1.24 & -0.01615 & -1.31 & -0.01757 & -1.25 \\
\hline ROE & -0.02133 & -0.87 & & & -0.01449 & -0.59 \\
\hline ROA & & & -0.15024 & -1.09 & & \\
\hline Size & 0.01987 & 0.99 & 0.02243 & 1.11 & 0.01966 & 0.98 \\
\hline R-square & \multicolumn{2}{|c|}{0.0105} & \multicolumn{2}{|c|}{0.0139} & \multicolumn{2}{c|}{0.0110} \\
\hline
\end{tabular}

\section{Discussion}

This paper aims to assess how the E\&M industry perceives SEO events by investigating the behavior of the E\&M firms' stock prices in response to these financial events. The E\&M industry has experienced tremendous growth globally and is attracting increasing attention from investors because it is facing a new chapter with the development of new technologies. For firms in the E\&M industry, raising capital is an important strategy for promoting their growth. This business environment raised the following questions: Can previous market-based results regarding the effect of SEOs be applied to the E\&M industry as well? In terms of the key factors affecting stock price movements, identified in previous studies analyzing samples comprising firms from heterogeneous industries, do they play similar roles in the E\&M industry? If these returns and factors behave differently in the E\&M industry, current and potential stock market investors, as well as financial managers of E\&M firms, should exercise caution when making financial decisions.

First, our findings reveal that stock prices in the E\&M industry respond differently, compared with the market-wide results. The positive stock price response in the Korean E\&M industry indicates that the stock market views SEOs as an optimistic signal for newly-raised stock to be utilized in a way that maximizes firm value. This supports the investment opportunity hypothesis asserted by McConnell and Muscarella[6]. Second, when examining factors contributing to the magnitude of stock price reactions regarding SEOs at the market-level, they showed no meaningful influence in the E\&M industry. These findings are important because they provide stock market participants with additional insights into the effect of SEOs at the industry level, specifically the E\&M industry, and fill in the gaps in existing literature.

\section{Conclusion}

Firms have adopted SEOs as a crucial strategy for sustainable growth and expansion. While 
numerous studies have analyzed the effect of SEOs, most have ignored the possibility of different effects in specific industries. This study aims to fill this gap. Our primary findings are as follows. First, in general, stock prices respond favorably to SEO announcements in the E\&M industry. Second, this phenomenon is more profound for non-public SEOs than public SEOs. Third, no meaningful influence of firm characteristics is observed in the E\&M industry. These results suggest that researchers should be careful when using samples collected from heterogeneous industries. Potential shareholders and policymakers also should exercise caution in applying these research results when making financial decisions, when they are interested in a specific industry. Although beyond the scope of this study, it would be interesting if future research could determine the key factors affecting the stock price responses to SEOs at the industry level.

\section{References}

[1] PricewaterhouseCoopers, Global Entertainment and Media Outlook: 2018-2022, PWC, https://www.pwc.ru/en/assets/mediaoutlook2018-eng.pdf, Jan 31 (2020)

[2] P. Asquith, D. W. Mullins, Equity Issues and Stock Price Dilution, Journal of Financial Economics, (1986), Vol.15, No.1-2, pp.61-89.

[3] D. Galai, R. W. Masulis, The Option Pricing Model and Risk Factor of Stock, Journal of Financial Economics, (1976), Vol.3, No.1-2, pp.53-81.

[4] S. Myers, N. Majluf, Corporate financing and investment decisions when firms have information that investors do not have, Journal of Financial Economics, (1984), Vol.13, No.2, pp.187-221.

[5] S. A. Ross, The Determination of Financial Structure: The Incentive-Signalling Approach, The Bell Journal of Economics, (1977), Vol.8, No.1, pp.23-40.

[6] J. J. McConnell, C. J. Muscarella, Corporate capital expenditure decisions and the market value of the firm, Journal of Financial Economics, (1985), Vol.14, No.3, pp.399-422.

[7] Y. Cheon, A Study on Relationship between Leisure Motivation and Leisure Attitude of a Hospitality Industry Member, World Journal of Accounting, Finance and Engineering, (2018), Vol.2, No.1, pp.13-18.

[8] M. Kim, The FDI Determinants of Indian Banking Sector, International Journal of Business Policy and Strategy Management, (2017), Vol.4, No.1, pp.59-64.

[9] Y. Kim, The Effect of Individual Variables on the Income of Workers in the IT Area, World Journal of Accounting, Finance and Engineering, (2018), Vol.2, No.1, pp.1-6.

[10] R. Lajevardi, An Organization Budgetary Control System Links with Performance Management and Financing Strategy in Entrepreneurship, World Journal of Accounting, Finance and Engineering, (2017), Vol.1, No.1, pp.15-30. 
[11] K. Chan, Y. C. Chan, Price informativeness and stock return synchronicity: Evidence from the pricing of seasoned equity offerings, Journal of Financial Economics, (2014), Vol.114, No.1, pp.36-53.

[12] X. Gao, J. R. Ritter, The marketing of seasoned equity offerings, Journal of Financial Economics, (2010), Vol.97, No.1, pp.33-52.

[13] Y. Huang, K. Uchida, D. Zha, Market timing of seasoned equity offerings with long regulative process, Journal of Corporate Finance, (2016), Vol.39, pp.278-294.

[14] A. M. Hibbert, Q. Kang, A. Kumar, S. Mishra, Heterogeneous beliefs and return volatility around seasoned equity offerings, Journal of Financial Economics, (2020), Vol.137, No.2, pp.571-589.

[15] L. V. A. Colombo, M. Botta, Seasoned Equity Offering Announcements and the Returns of European Bank Stocks and Bonds, Applied Economics, (2019), Vol.51, No.13, pp1339-1359.

[16] H. Li, H. Liu, C. Veld, The effects of bank regulation stringency on seasoned equity offering announcements, Journal of International Money and Finance, (2019), Vol.91, pp.71-85.

[17] H. Chen, N. Dai, J. D. Schatzberg, The choice of equity selling mechanism: PIPEs versus SEOs, Journal of Corporate Finance, (2010), Vol.16, No.1, pp.104-119.

[18] A. Gomes, G. Phillips, Why do public firms issue private and public securities?, Journal of Financial Intermediation, (2012), Vol.21, No.4, pp.619-658.

[19] S. Dahiya, L. Klapper, H. Parthasarathy, D. Singer, Equity raising by Asian firms: Choosing between PIPEs and SEOs, Journal of Corporate Finance, (2017), Vol.45, pp.64-83. 